\title{
Propositions on the Relationships between Technology Complexity, Industry 4.0, and Halal Sustainability
}

\author{
Mohamad Faizal Ahmad Zaidi \\ School of Technology Management \& Logistics, College of Business \\ Universiti Utara Malaysia, 06010 Sintok Kedah Malaysia
}

\begin{abstract}
Halal industry is currently one of the fastest growing market segments in the world. With the emerging of IR4.0, the future growth of Halal industry and its sustainability can be affected by the advancement of technology. Technology has continuously assimilated in every aspect of our live from consumerization, commercialization, and industrialization to infrastructure. Even though many factors may have collectively contributed towards better understanding of Halal sustainability, this article focuses only on the technological aspects of Halal in the face of IR4.0. With this focus, four components of technology comprising of technoware, humanware, infoware, and orgaware are discussed. Although each components of technology have been fairly studied in the previous Halal literature, most of them were not specifically emphasized on the sustainability issues. From DCs point-of-view, a firm that is capable of managing the complexity in the components of technology will become more sustainable at Halal marketplace under dynamic environment. A framework is proposed to explain how the technology complexity together with the environmental factors (opportunities and threats of IR4.0) can be affecting Halal sustainability. This article has proposed the complexity in each components of technology will positively affect Halal sustainability. Accordingly, the opportunities of IR4.0 is proposed to have a positive direct and moderation effects on the relationships between technology complexity and Halal sustainability, whereas the threats of IR4.0 will have a negative direct and moderation effects on the relationships.
\end{abstract}

\section{Key words: Dynamic capabilities $\cdot$ Humanware $\cdot$ Industry $4.0 \cdot$ Infoware $\cdot$ Orgaware $\cdot$ Technoware}

\section{INTRODUCTION}

Technology exists in various forms and shapes of resources including artifacts, processes, structures, and skills [1]. From resource-based theory (RBT), any form and shape of these resources have the potential to be a strategic resource, where the complexity in them can explain the source of sustainable competitive advantage. One of the famous concepts under RBT that emphasized on the importance of resources reconfiguration under rapidly technological change is dynamic capabilities (DCs) [2]. From DCs point-of-view, technology can be treated as a strategic resource where the complexity in technology can be the reason for sustainable competitive advantage. Along the same line, a concept of technology for resources transformation was introduced three decades ago emphasizing on four components of technology comprising of technoware, humanware, infoware, and orgaware [3].
This concept enables the levels of sophistication (complexity) in the components of technology to be examined and understood as an important strategic resource for economic growth [4].

In the meantime, Muslims are currently representing no less than $23 \%$ (or one fourth) of the world population and expected to increase up to $26 \%$ in 2030 and will reach $30 \%$ by the year 2050 [5]. As a result, Halal industry has becoming one of the fastest growing market segments in the world valued at about USD 560 billion a year covering wide category of products from food and beverage, pharmaceutical and health, cosmetics, and tourism. Accordingly, agriculture, logistics, pharmaceutical, cosmetics, travelling, and Islamic finance have turned up to be the most growing Halal sectors [6]. With increasing size of demands, the needs of Muslims population for Halal products cannot be simply ignored. In relation to DCs, a previous study has shown the importance of resources and

Corresponding Author: Mohamad Faizal Ahmad Zaidi, School of Technology Management \& Logistics, College of Business Universiti Utara Malaysia, 06010 Sintok Kedah Malaysia 
capabilities for enhancing Halal sustainability [7]. Therefore, despite of Halal industry has emerged into one of rapidly growing new sectors in global economy; it still faces various challenges that may affect the sustainability.

In general, Halal means permitted, allowed, lawful or legal [5]. In order to fulfil increasing demands of Muslims population on Halal products, the application of modern technology is getting more important for Halal sustainability. In fact, Halal production systems can be identified with a series of technology extended from suppliers to consumers. In Halal food for example, technology exists in various stages of production systems from slaughtering of raw material to processing, handling, packaging, storing, transportation, and distribution of the finished products [6]. This shows that technology is not only applied to the physical production of Halal products, but also in the logistical and other aspects of Halal. Due to the economic value of Halal industry, and as Halal is not simply a religion issue but an opportunity to create competitive advantage [8], Halal has becoming a relevant topic to talk about sustainability. This article aims to develop a conceptual framework with propositions on the relationships between technology complexity, Industry 4.0 (IR4.0), and Halal sustainability from DC point-of-view.

\section{ELEMENTS OF HALAL SUSTAINABILITY}

The concept of sustainable development lies on three pillars of economic, social, and environmental sustainability. In general, economic sustainability is characterized with the terms growth, development, productivity, and trickle down, whereas social sustainability is related with the terms equity, empowerment, accessibility, participation, sharing, cultural identity, and institutional stability. Meanwhile, environmental sustainability is associated with the terms ecosystem integrity, carrying capacity and biodiversity [9]. A previous study has found that economic sustainability can be indicated by the treasury, result of work, investment, return on each deal, amount of won tenders or contracts, amount of productivity, number of satisfied customers, and design aspect of the product, etc. Social sustainability is indicated by the number of satisfied employees, amount of local production, amount of local employment, and health, etc. Meanwhile, environmental sustainability is indicated by the amount of water used, amount of energy used, amount of recycled materials used, quality of the product, amount of transportation, and lifetime of the products, etc. [10].

In general, the concept of sustainability can be explained with Halal principles [11], which provide guideline on the production, handling, and processing of Halal goods. This implies the scope of studies on Halal sustainability is not confined in a single area only. In food industry for example, Halal sustainability is studied with the principles of environmental friendly, fair trade, food safety, and animal welfare [12]. In logistics, the issues are on traceability and accessibility of product information for enhancing Halal sustainability [13]. Other example is like Halal sustainability issue through Halal certification [14], and green issue on managing Halal foods supply chain [15]. At this stage of discussion, the article is treating economic, social, and environmental sustainability as equally important elements of Halal sustainability.

\section{COMPONENTS OF TECHNOLOGY FOR HALAL}

Technology capability can be understood as a strategic tool for resource transformation. This capability comprises of four components of technology, namely technoware, humanware, infoware, and orgaware [3]. These components which are common in features (between firms), but idiosyncrasy in details (within firm) can be considered as a form of DCs [16]. In general, technoware can be referred to all kinds of materials, tools, equipment, machines, facilities, and other physical artefacts necessary for production systems, such as in the case of transforming specific inputs into desirable outputs. In detail, technoware can be seen as directly involved in the production systems, and also indirectly applied in managing the products, such as in the case of inventory or transportation systems. To a greater extend, technoware can also be the end product itself, which means technoware can exists in both product and production technology [4]. Meanwhile, humanware is a critical component of technology for human capital development. It refers to all kinds of skills, proficiencies, knowledge, experiences, and labor forces that directly involved in the physical production of products, such as the operators that handle the equipment, and operating the machineries. Humanware is used to equip the firms with skillful, knowledgeable, experienced, and well-trained human resources. It can also be indirectly involved in the physical production of products, such as where senior managers involved in problem-solving under product planning and development.

Subsequently, infoware can be referred to all kinds of data, statistics, records, and information in relation to product specifications, designs, manuals, and instructions for production and communications. In contrast to technoware that focuses on product (hard) technology, infoware focuses on process (soft) technology that is used to determine (but not limited to) what, when, where, and how the specific products are produced. As such, infoware is not just crucial within the production systems per se but also important within the supply-chain of the products. Lastly, orgaware is all kinds of internal and external practices, 
procedures, policies, requirements, regulations, and structures that influence the decisions and actions made by the firms. It influences the firms' future-direction, goals, decision-making, problem-solving, training and development, investment, and acquisition of resources [4]. In the context of Halal industry, technoware is important to physically acquire, produce, process, handle, and distribute Halal products and services. Humanware is needed to operate, supervise, coordinate, execute, manage, direct, and lead all activities on Halal products and services. Infoware is relied on to seek, gather, store, control, and disseminate information and communication on Halal products and services. While, orgaware is relied on to plan, implement, and control current development and future direction of Halal products and services. To get a better understanding of the topic, examples of studies from Halal literature were identified, and selected in line with the components of technology (see Table 1).

Tab. 1: Examples of Halal studies on technology

\begin{tabular}{llll}
\hline Components & Areas & Focuses & Sources \\
\hline Technoware & Health & Dental materials & {$[17]$} \\
& Food & Slaughter methods & {$[18]$} \\
& Food & Lean tools and techniques & {$[19]$} \\
& Food & Halal packaging & {$[20]$} \\
\hline Humanware & Logistics & Employee perception & {$[21]$} \\
& Logistics & Human capital development & {$[22]$} \\
& General & Executives' knowledge & {$[23]$} \\
\hline Infoware & General & Halal tracking system & {$[24]$} \\
& Food & Halal traceability system & {$[25]$} \\
& General & Halal detection application & {$[26]$} \\
& General & Android barcode scanner & {$[27]$} \\
& Logistics & ICT system adoption & {$[28]$} \\
\hline Orgaware & Logistics & Shari'a governance & {$[29]$} \\
& General & Consumer protection law & {$[30]$} \\
& Services & Halal standard & {$[31]$} \\
& Food & Halal standard & {$[32]$} \\
& Cosmetics & Assurance system requirements & {$[33]$} \\
\hline
\end{tabular}

Based on the examples in Table 1, studies on technoware were found to focus on lean tools and techniques, slaughter technologies, and packaging in food. Studies on humanware were focused on human capital development, and knowledge. Studies on infoware were focused on the adoption of information and communication technology (ICT), and tracking and tracing system in Halal logistics, validation system in food, and product recognition system. Meanwhile, examples of studies on orgaware were found to focus on much wider areas, such as on Halal resources acquisition in logistics, Halal standard for hotel services, and Halal assurance system requirements for cosmetics. This suggests that Halal studies focusing on each components of technology are available in literature. Despite of that, the numbers of study focusing on technology capability on Halal sustainability is still limited. Even the work of [7] on Halal sustainability was not focusing on the components of technology and its complexity. Therefore, more discussion is needed as to understand how the complexity in the components of technology can affect Halal sustainability.

\section{ENVIRONMENTAL FACTORS OF INDUSTRY 4.0}

IR4.0 is synonymous with the fourth industrial revolution in the domain of production systems [17]. This current industrial revolution is being observed through the paradigm shift from widespread digitalization of production, e.g., programmable logic controller to advanced digitalization systems integration with the Internet of Things (IoT) and smart objects, enabling the products to determine their own production processes [18]. Since IR4.0 is revolutionary in nature, so what exactly does this means? According to Merriam-Webster online dictionary, revolution refers to "a sudden, radical, or complete change" or "a changeover in use or preference especially in technology". In a similar fashion, Cambridge Dictionary defines revolution as "a very important change in the way that people do things". Meanwhile, Oxford Dictionaries defines revolution as "a dramatic and wide-reaching change in conditions, attitudes, or operation". One thing similar about these definitions is that revolution connotes change. In the context of industrial production, this means firms must adapt to the change and the way they produce products. The foundation of IR4.0 is based on nine pillars of technological advancement consisting of additive manufacturing, augmented reality, autonomous robots, big data analytics, cloud computing, cybersecurity, IoT, simulation, and system integration [19]. These technological advancements have created both opportunities and threats on many firms competing in various economic sectors.

A recent survey on developed countries has found a significant interest in the challenge imposed by IR4.0 on the firms. It was found majority of the respondents recognized IR4.0 as an opportunity to improve the firms' competitiveness, while a small group of respondents do perceived IR4.0 as a threat [20]. In the context of sustainability, opportunities from IR4.0 can be classified into strategy, operations, environment and people, while challenges can be classified into competitiveness and future viability, organizational and production fit, and employee qualification and acceptance [21]. Because of changing nature of technology under IR4.0, the new source of capabilities will emerge, while the existing one will become irrelevant for sustaining competitive advantage. As a result, firms worldwide have to prepare and get ready with the change [22]. For this reason, changing of the environment caused by the opportunities and threats of IR4.0 may as well affecting Halal industry and its sustainability. 


\section{A CONCEPTUAL FRAMEWORK FROM DYNAMIC CAPABILITIES POINT-OF-VIEW}

From DCs point-of-view, different firms are possessing different set of resources, where they will respond to the opportunities and threats differently due to different experiences and learning, and will reconfigure the internal set of resources based on their existing experience and knowledge [23]. Therefore, a firm that can address the external environment (IR4.0), and reconfigure the internal resources (components of technology) better than the others will be more successful at marketplace. However, the reconfigured internal resources must be complex, such as valuable, rare, inimitable, and non-substitutable (VRIN) to achieve Halal sustainability. With this in mind, a conceptual framework to understand the relationships between the complexity in the components of technology, environmental factors, and Halal sustainability is proposed (see Figure 1).

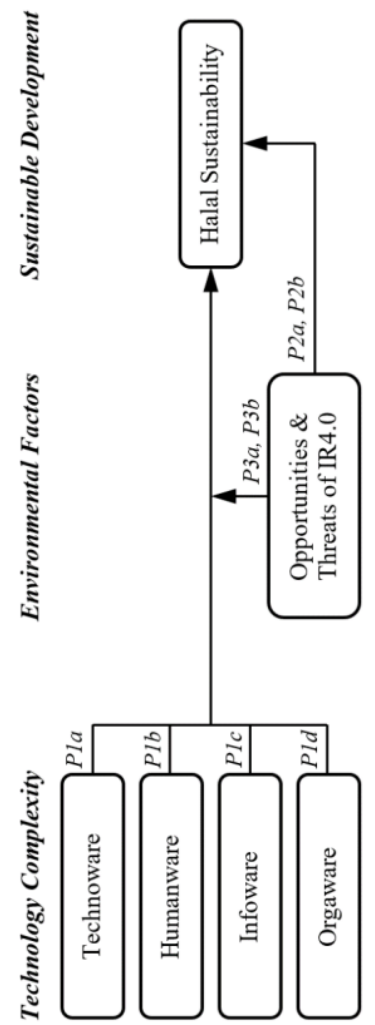

Fig. 1: A proposed conceptual framework

\section{PROPOSITIONS ON TECHNOLOGY COMPLEXITY AND HALAL SUSTAINABILITY}

How would the complexity in the components of technology be affecting Halal sustainability? According to DCs point-of-view, not all resources are equally important as some of them are more transferable, replaceable, or substitutable than the others. When these resources can be replicated or replaced, they will become less valuable to be a source of competitive advantage. The uniqueness of each components of technology will enable different firms to perform differently. As a result, firm that possesses the components of technology with VRIN characteristics will have higher chances to sustain competitive advantage [2]. This means in order to create Halal sustainability, not just the right technoware, humanware, infoware, and orgaware need to be instated, their complexity also needs to be understood and managed as well.

In general, complexity in technoware can be increased with the integration of tools, machines, equipment, and facilities via automation and computerization. Complexity in humanware can be increased with the amplification of skills, experiences, proficiencies, and knowledge via continuous learning and training. Complexity in infoware can be increased with the accumulation of data, records, statistics, and information via active communication and networking. Similarly, complexity in orgaware can be increased with the reformation of policies, practices, procedures, and structures via international trading, globalization, and liberalization of economy [4]. In regard to Halal industry, the complexity in the components of technology can be seen as the key determinant for achieving Halal sustainability. From DCs point-of-view, each components of technology need to be built, harnessed, maintained, and controlled in order to create complexity within them, which is important to achieve Halal sustainability. As a result, this article proposes,

Proposition 1a: Complexity in technoware will positively affect Halal sustainability

Proposition 1b: Complexity in humanware will positively affect Halal sustainability

Proposition 1c: Complexity in infoware will positively affect Halal sustainability

Proposition 1d: Complexity in orgaware will positively affect Halal sustainability

\section{PROPOSITIONS ON ENVIRONMENTAL FACTORS OF INDUSTRY 4.0 AND HALAL SUSTAINABILITY}

The external environmental factors are hardly controlled by any firm. This means any changes to these factors, such as economic, social, technological, environmental, political, and legal, will create opportunities and threats to both existing firms and potential newcomers. As such, managing technological change is crucially important, where insufficient reaction of firms to the change can lead to their demise [24]. In the recent years, IR4.0 has becoming one most important agent of change driven by nine technological advancements. Changing in technological resources will bring new challenge to the 
firms [25]. Hence, they will need to confront with not just the turbulent in marketplace but also the uncertainty of technologies [26]. From DCs point-of-view, technological turbulence (caused by IR4.0) can potentially create both opportunities and threats to the firms. The important of opportunities and threats were highlighted in the microfoundations of DCs that emphasized on the opportunity sensing, opportunity seizing, and managing threats [27]. A recent study on sustainability has found that the opportunities in environment are positive towards IR4.0, while challenges are negative towards IR4.0 [21]. As a result, this article proposes,

\section{Proposition 2a: Opportunities from IR4.0 will positively affect Halal sustainability \\ Proposition 2b: Threats from IR4.0 will negatively affect Halal sustainability}

Under environmental change, even resources that are hard to duplicate can becoming irrelevant. As a result, the existing complexity in the components of technology will be changing due to the opportunities and threats of IR4.0. In order to maintain Halal sustainability, firms have to screen, identify, select, and manage both opportunities and threats, and reconfigure the components of technology accordingly. Through the interactions between the components of technology and the environmental factors, Halal sustainability is not just affected by the level of technology complexity possessed by the firm, but also the opportunities and threats of IR4.0. This shows that the internal and external environments are co-exist at affecting Halal sustainability. As a result, this article proposes,

\section{Proposition 3a: Opportunities from IR4.0 will positively moderate the effects of technology complexity on Halal sustainability \\ Proposition 3b: Threats from IR4.0 will negatively moderate the effects of technology complexity on Halal sustainability}

\section{DISCUSSIONS}

To recapitulate what was said earlier, DCs are a popular concept that explains the firm's competitive advantage via reconfiguration of internal resources in response to rapidly technological change. Because of technological advancement under IR4.0, Halal industry just like any other industries around the world is affected by the change. As Halal industry is one of the fastest growing industries in the world, Halal sustainability has started to be a concern under IR4.0 as to remain competitive. For this reason, a conceptual framework with propositions was discussed to demonstrate how DCs concept is applied towards Halal sustainability. It was proposed the firm that can reconfigure its components of technology in line with the opportunities and threats of IR4.0 will be able to sustain competitive advantage. This will happen when the complexity achieved during technology reconfiguration is hard to be understood and duplicated by others (due to VRIN characteristics).

Despite of having around since three decades ago, the four components of technology have seen not many studies focusing on them. Knowing each components of technology is important as it enable the firm to scrutiny technology in a more organized way into technoware (e.g., equipment and machineries), humanware (e.g., knowledge and skills), infoware (e.g., designs and specifications ), and orgaware (e.g., policy and procedure). By increasing the firm knowledge on each components of technology will help them to understand the type of technology affected by the technological advancement. As a result, the firm will be able to reconfigure the right types of technology in response to the source of change. Hence, the firm ability to fully understand the relationships between each components of technology and reconfigure them according to the opportunities or threats of IR4.0 will be able to sustain competitive advantage. In contrast, the firm will be in trouble to guard its competitive advantage under technological change if the firm is struggling to understanding its own components of technology, unable to reconfigure them correctly, and difficult to increase the complexity of the technology.

Although this article is considering all elements of sustainable development for Halal sustainability, it will be interesting to know which of the elements - economic, social, or environmental sustainability - is the main focus of Halal industry, and which one is the most affected by the components of technology, and the opportunities and threats of IR4.0. Therefore, for the next stage of study, each components of technology, the opportunities and threats of IR4.0, and the elements of Halal sustainability need to be detailed out for empirical research.

\section{CONCLUSIONS}

Halal industry is currently one of the fastest growing economic segments in the world. This industry provides various products from food and beverage, pharmaceutical and health, cosmetics, and tourism to billions of Muslims all over the world. With the advancement of technology, Halal growth and sustainability can be affected by IR4.0. From DCs point-of-view, technology can be treated as a strategic resource to achieve Halal sustainability. Due to this reason, four components of technology (i.e., technoware, humanware, infoware, and orgaware) for resource transformation were highlighted. In this case, the four 
components of technology can be considered as a form of DCs as they are common in features (between firms), but idiosyncrasy in details (within firm). Theoretically, firm can sustain competitive advantage when the components of technology are valuable, rare, inimitable, and nonsubstitutable, which is also characterizing the complexity in technology. As some components of technology can be more important at one time than the others, firm that is capable of reconfiguring and creating complexity in the right components of technology under environmental change will be more successful at the marketplace. Accordingly, a conceptual framework is proposed to show how the complexity in the components of technology, together with the environmental factors (opportunities and threats of IR4.0) may affect Halal sustainability. This article has proposed the complexity in each components of technology to directly and positively affect Halal sustainability. Meanwhile, the opportunities from IR4.0 are proposed to have a direct and positive moderation effects on the relationships between technology complexity and Halal sustainability. In contrast, the threats from IR4.0 will have a direct and negative moderation effects on the relationships.

\section{REFERENCES}

1. Khalil, T. M. (2000). Management of technology: The key to competitiveness and wealth creation. McGraw-Hill Science, Engineering \& Mathematics.

2. Teece, D. J., Pisano, G., \& Shuen, A. (1997). Dynamic capabilities and strategic management. Strategic Management Journal, 509533.

3. Sharif, M. N., Bowonder, B., Cho, E., Miyake, T., Prapaporn, P., \& Ramanathan, K. (1987). Components of technology for resources transformation. Technological Forecasting \& Social Change, 32(1), 19-35.

4. Sharif, N., \& Ramanathan, K. (1991). Measuring contribution of technology for policy analysis. System Dynamics, 91, 534-542.

5. Elasrag, H. (2016). Halal industry: Key challenges and opportunities. Munich Personal RePEc Archive (MPRA) Paper no. 69631.

6. Dar, H., Azmi, N., Rahman, R., \& Malik, R. (Eds.). (2013). Global Islamic Finance Report 2013. London: Edbiz Consulting.

7. Karia, N., \& Asaari, M. H. A. H. (2015). Enhancing Halal sustainability: Resources and capabilities of operations in third-party logistics (3PL). Advances in Business \& Economic Development, 206-211.

8. Yeo, B. L., Mohamed, R. H. N., \& Muda, M. (2016). A study of Malaysian customers purchase motivation of Halal cosmetics retail products: Examining theory of consumption value and customer satisfaction. Procedia Economics and Finance, 37, 176-182.
9. Basiago, A. D. (1999). Economic, social, and environmental sustainability in development theory and urban planning practice. The Environmentalist, 19(2), 145-161.

10. Sundin, E., Nässlander, E., \& Lelah, A. (2015). Sustainability indicators for small and medium-sized enterprises (SMEs) in the transition to provide product-service systems (PSS). Procedia CIRP, 30, 149-154.

11. Zainalabidin, M., Golnaz, R., \& Mad, N. S. (2011). The complementary effect of Halal principles and sustainable concept. Journal of Environmental Science and Engineering, 5(5), 652-659.

12. Rezai, G., Mohamed, Z., \& Shamsudin, M. N. (2015). Can Halal be sustainable? Study on Malaysian consumers' perspective. Journal of Food Products Marketing, 21(6), 654-666.

13. A-Jalil, E. E. (2018). Logistical indicators for enhancement of Halal sustainability. International Journal of Islamic Marketing and Branding, 3(3), 223-231.

14. SyedMarzuki, S. Z., Hall, C. M., \& Ballantine, P. W. (2013). Sustaining Halal certification at restaurants in Malaysia. In Hall, C. M., \& Stefan, G. (Eds.), Sustainable Culinary Systems: Local Foods, Innovation, and Tourism \& Hospitality, 270-288. Routledge.

15. Chain, M. H. F. S. (2013). Environmental concern in managing Halal food supply chain. American Journal of Environmental Science, 9(3), 240-246.

16. Eisenhardt, K.M., \& Martin, J.A. (2000). Dynamic capabilities: What are they? Strategic Management Journal, 1105-1121.

17. Schröder, C. (2016). The Challenges of Industry 4.0 for Small and Medium-sized Enterprises. Bonn: Friedrich-Ebert-Stiftung.

18. Lasi, H., Fettke, P., Kemper, H. G., Feld, T., \& Hoffmann, M. (2014). Industry 4.0. Business \& Information Systems Engineering, 6(4), 239-242.

19. Rüßmann, M., Lorenz, M., Gerbert, P., Waldner, M., Justus, J., Engel, P., \& Harnisch, M. (2015). Industry 4.0: The future of productivity and growth in manufacturing industries. Boston Consulting Group, 9.

20. Ślusarczyk, B. (2018). Industry 4.0: Are we ready? Polish Journal of Management Studies, 17(1), 232-248.

21. Müller, J. M., Kiel, D., \& Voigt, K. I. (2018). What drives the implementation of Industry 4.0? The role of opportunities and challenges in the context of sustainability. Sustainability, 10(247), 1-24.

22. Zaidi, M.F.A., \& Belal, H.M. (2019). A preliminary study to understand the SMEs' readiness on IoT in Malaysia. International Journal of Accounting, Finance and Business, 4(19), 1-12.

23. Zaidi, M. F. A., \& Othman, S. N. (2014). The concept of dynamic capability for managing technology and change. Strategic Management Quarterly, 2(2), 93-108.

24. Lichtenthaler, E. (2004). Technological change and the technology intelligence process: A case study. 
Journal of Engineering and Technology Management, 21, 331-348.

25. Chen, H.-H., \& Lee, P.-Y. (2009). The driving drivers of dynamic competitive capabilities: A new perspective on competition. European Business Review, 21(1), 78-91.

26. Kylaheiko, K., \& Sandstrom, J. (2007). Strategic options-based framework for management of dynamic capabilities in manufacturing firms. Journal of Manufacturing Technology Management, 18(8), 966-984.

27. Teece, D. J. (2007). Explicating dynamic capabilities: The nature and microfoundations of (sustainable) enterprise performance. Strategic Management Journal, 28(13), 1319-1350. 